\title{
Electrochemical Corrosion Behavior of the Copper Current Collector in the Electrolyte of Lithium-ion Batteries
}

\author{
Shuowei Dai ${ }^{1,2}$, Jian Chen ${ }^{1,2}$, Yanjie Ren ${ }^{1,2, *}$, Zhimin Liu ${ }^{1,2}$, Jianlin Chen ${ }^{1,2}$, \\ Cong $\mathrm{Li}^{1,2}$, Xinyuan Zhang ${ }^{1,2}$, Xiao Zhang ${ }^{1,2}$ and Taofang Zeng ${ }^{1,2}$ \\ ${ }^{1}$ School of Energy and Power Engineering, Changsha University of Science \& Technology, Changsha, \\ Hunan 410014, China \\ ${ }^{2}$ Key Laboratory of Energy Efficiency and Clean Utilization, Education Department of Hunan \\ Province, Changsha University of Science \& Technology, Changsha, Hunan 410014, China \\ *E-mail: yjren1008@163.com
}

doi: $10.20964 / 2017.11 .28$

Received: 24 July 2017 / Accepted: 3 September 2017 / Published: 12 October 2017

Copper is usually used as an anode current collector in lithium-ion batteries. Its stability in the organic electrolyte impacts the performance of the lithium-ion battery. In this paper, the corrosion mechanism of the copper current collector in the electrolyte of lithium-ion batteries was examined by electrochemical impedance spectroscopy(EIS) and polarization measurements. The microstructures of copper were observed by scanning electron microscopy(SEM) and energy dispersive spectroscopy (EDS). The fitted results of electrochemical impedance spectroscopy showed that $R_{f}$ and $R_{t}$ increased at the initial stage of exposure to the electrolyte indicating that a protective layer formed. After exposure to the electrolyte for up to $720 \mathrm{~h}$, pitting holes could be clearly observed on the surface of copper.

Keywords: Lithium-ion Batteries, Copper current collector, Electrochemical impedance spectra, Corrosion mechanism

\section{FULL TEXT}

(C) 2017 The Authors. Published by ESG (www.electrochemsci.org). This article is an open access article distributed under the terms and conditions of the Creative Commons Attribution license (http://creativecommons.org/licenses/by/4.0/). 